\title{
THE NEAR-SOURCE GROUND MO'TION OF THE 6 AUGUST 1979 COYOTE LAKE, CALIFORNIA, EARTHQUAKE
}

\author{
By Hsui-Lin Liu and Donald V. Helmberger
}

\begin{abstract}
A finite fault striking $\mathrm{N} 24^{\circ} \mathrm{W}$ and extending to a depth of $10 \mathrm{~km}$ is proposed to explain the strong ground motion data for the 6 August 1979 Coyote Lake, California, earthquake ( $M_{L}=5.9$ ). Our source model suggests that right-lateral faulting initiated at a depth of $8 \mathrm{~km}$ and ruptured toward the south with a velocity of $2.8 \mathrm{~km} / \mathrm{sec}$. This unilateral rupture can explain the large displacement recorded south of the epicenter. However, the waveform coherency across an array south and southwest of the epicenter suggests that the rupture length is less than $6 \mathrm{~km}$. The maximum dislocation is about $120 \mathrm{~cm}$ in a small area near the hypocenter, and the total moment is estimated to be $3.5 \times 10^{24}$ dyne-cm. An abrupt stopping phase which corresponds to a deceleration of right-lateral motion can explain the high peak acceleration recorded at array station 6 . The stress drop in the hypocentral area is about 140 bars; the average stress drop over the entire rupture surface is $\mathbf{3 0}$ bars. The preferred finite-source model can predict the $P_{n 1}$ waveforms and the beginning features in the teleseismic seismograms. No clear arrivals can be observed in the near-source data for the possible second and third smaller events suggested by Nabelek (personal communication).
\end{abstract}

\section{INTRODUCTION}

The strong ground motions recorded at the Gilroy array and San-Martin CoyoteCreek (SMCC) station from the 6 August 1979 Coyote Lake, California, earthquake $\left(M_{L}=5.9\right)$ provide a good opportunity to investigate the faulting process along the Calaveras fault zone. From a seismological point of view, the near-in data reflects the most detailed information available about the faulting process, especially that portion of the fault which radiates the high-frequency energy. However, interpreting these details of the source process necessitates constructing source models with a large number of free parameters (e.g., rupture velocity, rupture direction, dislocation size, and distribution). Data from an array of near-source instruments are essential to reliably constrain these unknowns.

A detailed analysis of the strong ground motion data will be presented in this paper. In particular, we will demonstrate how to interpret the data in terms of fault size, rupture speed, rupture direction, and fault dislocation heterogeneity. We will then use our near-source model to interpret regional and teleseismic seismograms.

\section{SOURCE Location AND MEChanISM}

The epicenter of the Coyote Lake earthquake was located about $13 \mathrm{~km}$ northeast of Gilroy by the University of California, Berkeley (Uhrhammer, 1980). This location is about $3 \mathrm{~km}$ to the northeast of the location obtained by the U.S. Geological Survey as shown in Figure 1 (Lee et al., 1979). The Gilroy stations (GA-1, GA-2, GA-3, GA-4, and GA-6) and SMCC range from 2 to $16 \mathrm{~km}$ from the epicenter (Brady et al., 1979).

The first $P$-motion distribution indicates a nearly pure strike-slip mechanism with strike $\left(\mathrm{N} 24^{\circ} \mathrm{W}\right)$ parallel to the Calaveras fault (Lee et al., 1979). The teleseismic and regional first $P$ motions suggest a plane dipping $80^{\circ}$ to the northeast (see Figure 2). 
No clear surface faulting was found near the epicentral region. Right-lateral surface breakage of about $0.5 \mathrm{~cm}$ is reported near the junction of Highway 152 and the Calaveras fault and is marked as the shaded area in Figure 1 (Herd et al., 1979).

\section{Strong Ground Motion Data}

The recorded strong ground accelerations were corrected and integrated to velocities and displacements (Brady et al., 1979). We rotate the horizontal velocities into the radial and transverse components defined relative to source BK (shown in Figure 3). The arrows in Figure 3 indicate the $S$ arrivals and all traces start at the trigger time. The major signal is less than $2 \mathrm{sec}$ in duration at all stations. In general, the waveforms are very coherent across the Gilroy array although broader waveforms are observed on the tangential components southwest of the epicenter. Table 1 lists the station information and their peak amplitudes.

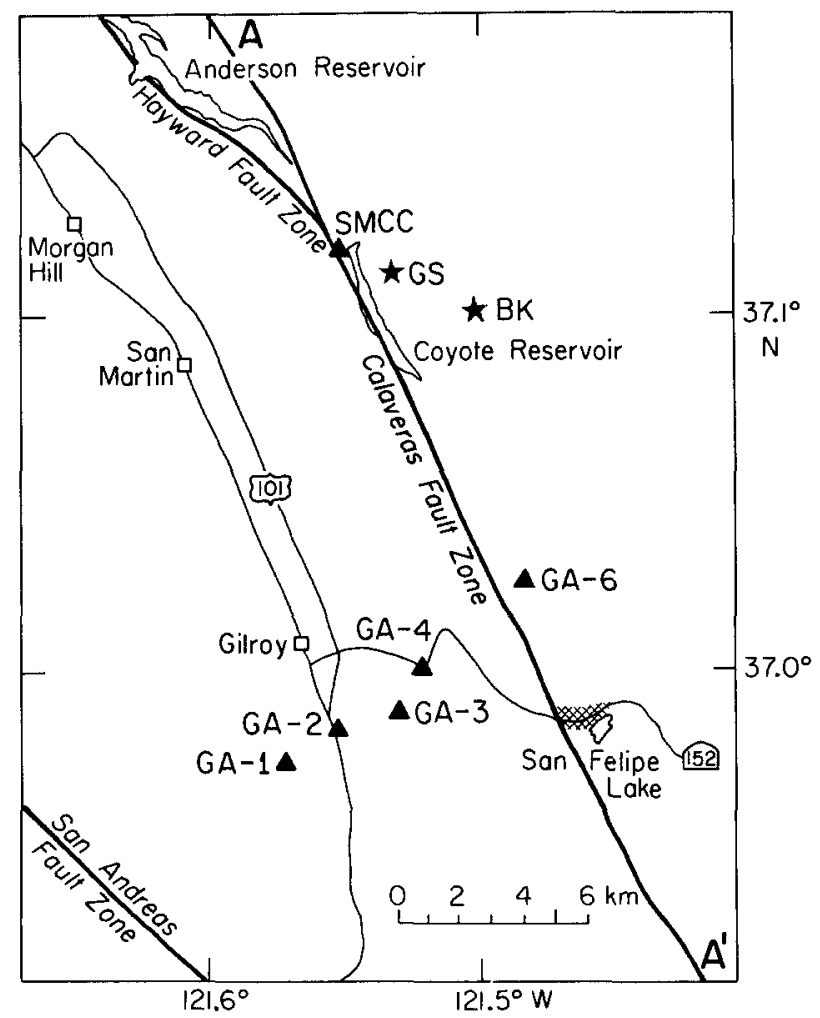

FIG. 1. Epicenter of the 6 August 1979 Coyote Lake, California, Earthquake. GS is the epicenter located by the U.S. Geological Survey and BK is the University of California Berkeley location. The solid triangles are the strong ground motion sites which include SMCC and the Gilroy array (GA-1, GA2, GA-3, GA-4, and GA-6). The shaded area near the junction of Highway 152 and the Calaveras fault zone is the location where a 0.5 -cm right-lateral surface breakage is reported.

Although the station SMCC which lies northwest of the epicenter has the shortest epicentral distance, its amplitudes are smaller than most of the southern stations, particularly station GA-6. One possible explanation for the difference in amplitude is the rupture direction along the fault. Since most of the aftershock activity was located south of San-Felipe, lateral rupture along the fault toward the station GA6 was postulated to explain the high-amplitude seismograms (Archuleta, 1979). The directivity effect will be analyzed later together with other array displacements. In addition, GA-6 lies close to an $\mathrm{SH}$ radiation maximum, and the $\mathrm{N} 230^{\circ} \mathrm{E}$ component 


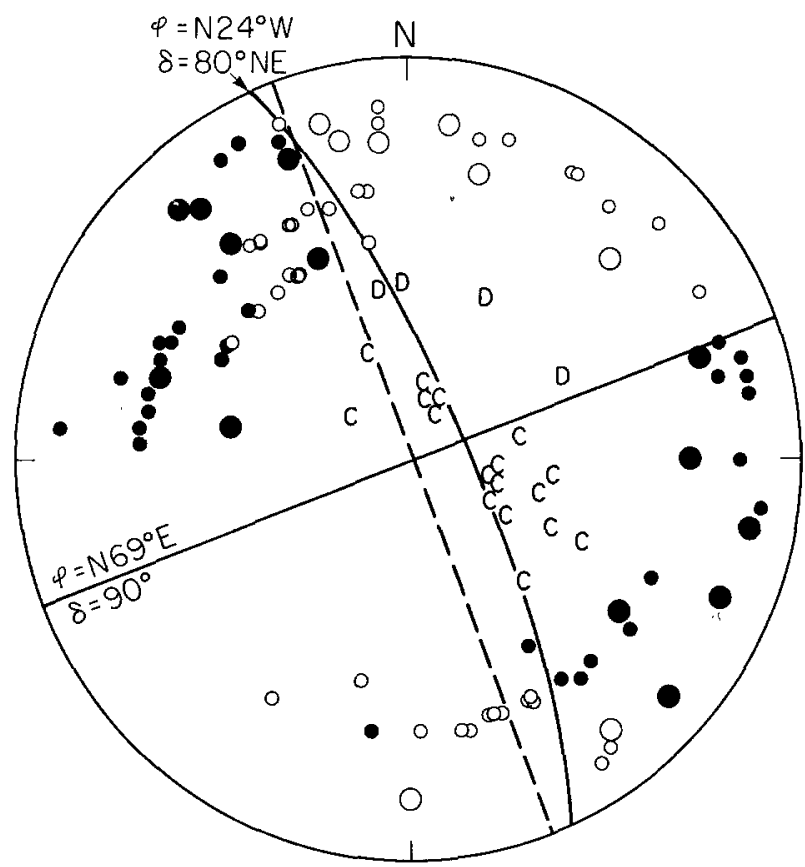

FIG. 2. The lower hemisphere equal-area projection of the first $P$ motions. The solid dots and circles are the local compressional and dilatational projections taken from Lee et al. (1979). C's and D's are, respectively, compressional and dilatational first $P$ motions from regional and teleseismic stations. The dashed line is the fault plane determined by Lee et al. (1979), and the solid line is the one determined in this study, which has an $80^{\circ}$ dipping to the northeast.

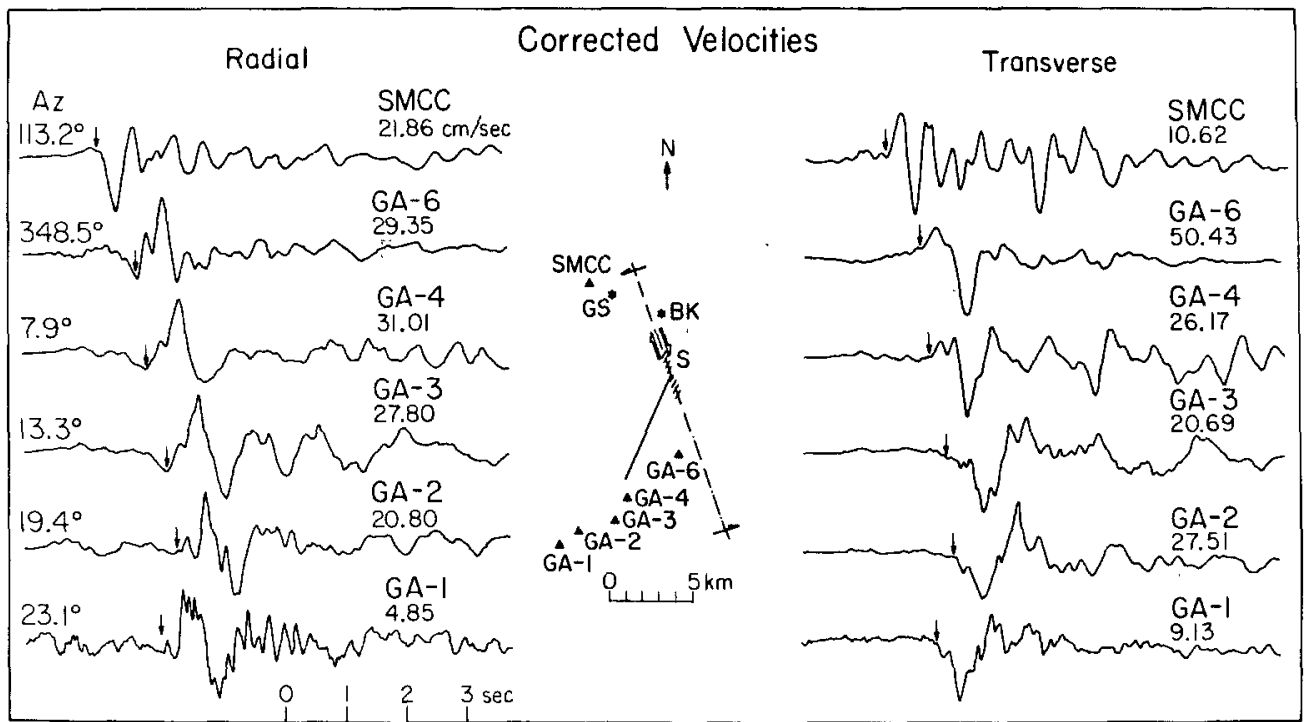

FrG. 3. The horizontal integrated velocities from SMCC and the Gilroy array. The data are rotated relative to the BK epicenter as transverse and radial components, as indicated by their back azimuths. The absolute amplitudes are indicated as those numbers with units of centimeters/second. The arrows indicate the $S$ arrivals.

is naturally rotated in the tangential direction. It seems that the radiation pattern also contributes to the high amplitude observed there.

Figure 4 shows the corrected acceleration (the maximum observed horizontal acceleration for this event) and the corresponding velocity and displacement re- 
corded at station GA- 6 on component $\mathrm{N} 230^{\circ} \mathrm{E}$. The displacement, with a peak value of about $10 \mathrm{~cm}$, is consistent with the right-lateral strike-slip faulting. However, the high acceleration (arriving near $2.5 \mathrm{sec}$ ) and the corresponding peak velocity indicate left-lateral motion, and are due to the decelerated motion at the end of the faulting process. An abrupt stopping of the rupture seems to be the most likely explanation for this high acceleration at station GA-6.

It can be seen in Figure 3 that the amplitudes vary slowly across the Gilroy array except for the most distant station GA-1. Station GA-1 has a very low amplitude signal compared to GA-2, which is only about $2 \mathrm{~km}$ away. The radiation pattern and rupture direction can not explain a factor of 3 amplitude difference. Joyner et al. (1981) interpreted this as an alluvium amplification effect on station GA-2. Nevertheless, the waveforms are quite similar at GA-2 and GA-1 for both horizontal components.

TABLE 1

Strong Ground Motion Stations and Data*

\begin{tabular}{|c|c|c|c|c|c|c|}
\hline Station & Coordinates & $\begin{array}{l}\text { S.P time } \\
\text { (sec) }\end{array}$ & Component & $\begin{array}{l}\text { Acceleration } \\
\left(\mathrm{cm} / \mathrm{sec}^{2}\right)\end{array}$ & $\begin{array}{l}\text { Velocity } \\
\text { (cm/sec) }\end{array}$ & $\begin{array}{l}\text { Displacement } \\
\text { (cm) }\end{array}$ \\
\hline \multirow[t]{3}{*}{ SMCC } & $37.118 \mathrm{~N}$ & 1.3 & $250^{\circ}$ & 245 & 20.5 & 2.4 \\
\hline & $121.550 \mathrm{~W}$ & & UP & 101 & 7,2 & 0.7 \\
\hline & & & $160^{\circ}$ & 138 & 11.5 & 1.1 \\
\hline \multirow[t]{3}{*}{ GA-6 } & $37.026 \mathrm{~N}$ & 1.5 & $320^{\circ}$ & 315 & 25.1 & 3.6 \\
\hline & $121.484 \mathrm{~W}$ & & UP & 147 & 16.5 & 3.1 \\
\hline & & & $230^{\circ}$ & 409 & 43.8 & 9.3 \\
\hline \multirow[t]{3}{*}{$\mathrm{GA}-4$} & $37.000 \mathrm{~N}$ & 2.2 & $360^{\circ}$ & 246 & 32.2 & 5.2 \\
\hline & $121.521 \mathrm{~W}$ & & UP & 409 & 15.4 & 2.5 \\
\hline & & & $270^{\circ}$ & 228 & 25.2 & 3.0 \\
\hline \multirow[t]{3}{*}{ GA-3 } & $36.991 \mathrm{~N}$ & 2.6 & $140^{\circ}$ & 246 & 29.4 & 5.7 \\
\hline & $121.536 \mathrm{~W}$ & & UP & 136 & 7.0 & 1.2 \\
\hline & & & $50^{\circ}$ & 252 & 16.9 & 3.7 \\
\hline \multirow[t]{3}{*}{ GA-2 } & $36.982 \mathrm{~N}$ & 2.7 & $140^{\circ}$ & 249 & 31.9 & 5.3 \\
\hline & $121.556 \mathrm{~W}$ & & UP & 162 & 6.6 & 1.0 \\
\hline & & & $50^{\circ}$ & 186 & 10.2 & 2.2 \\
\hline \multirow[t]{3}{*}{ GA-1 } & $36.973 \mathrm{~N}$ & 2.5 & $320^{\circ}$ & 111 & 10.3 & 1.7 \\
\hline & $121.572 \mathrm{~W}$ & & UP & 58 & 2.6 & 0.5 \\
\hline & & & $230^{\circ}$ & 84 & 4.0 & 0.7 \\
\hline
\end{tabular}

* The data are taken from Brady et al. (1979).

To model the strong ground motions, we locate the fault consistent with the available data, i.e., fault-plane geometry and observed radiation pattern. The focal mechanism from the first $P$ motions suggest a fault plane with similar strike to the Calaveras fault $\left(\mathrm{N} 24^{\circ} \mathrm{E}\right)$ and with $80^{\circ}$ dip to the east. The initial motion of the transverse and radial components of the near-source displacements are identified as the radiation from the hypocenter. The first arrivals seen on the transverse components reverse polarity between stations GA-3 and GA-4, indicating that a nodal line corresponding to $\mathrm{SH}$ waves from the initiation of rupture lies between these two stations (as indicated by the solid line in Figure 3). The azimuth of the nodal line is fixed to agree with the orientation of the fault plane, and the hypocenter of our source model is constrained to lie on that line. The first radial $S$ motion of stations GA-4 and GA-6 indicate that both stations lie to the west of a line defined 
by the fault strike. We, therefore, propose to model the near-source ground motions by a $10-\mathrm{km}$-long fault striking $\mathrm{N} 24^{\circ} \mathrm{W}$ and dipping $80^{\circ}$ to the northeast. The surface projection of the finite fault is indicated as the dashed line along $\mathrm{N} 24^{\circ} \mathrm{W}$ in Figure 3 , which is about $2 \mathrm{~km}$ east of the surface trace of the Calaveras fault. We suggest that the rupture started at the intersection of the $S H$ nodal line and fault strike direction indicated by the point $S$ in Figure 3 . We further suggest that most of the rupture occurred in a localized area just south of the hypocenter producing the short and coherent horizontal signals observed at different azimuths at the Gilroy array.

We also plot the near-source vertical velocities in Figure 5. The amplitude is about one-third of the horizontal motion. The downward solid arrows in Figure 5 indicate our expected $S$ arrivals determined from the horizontal components. How-

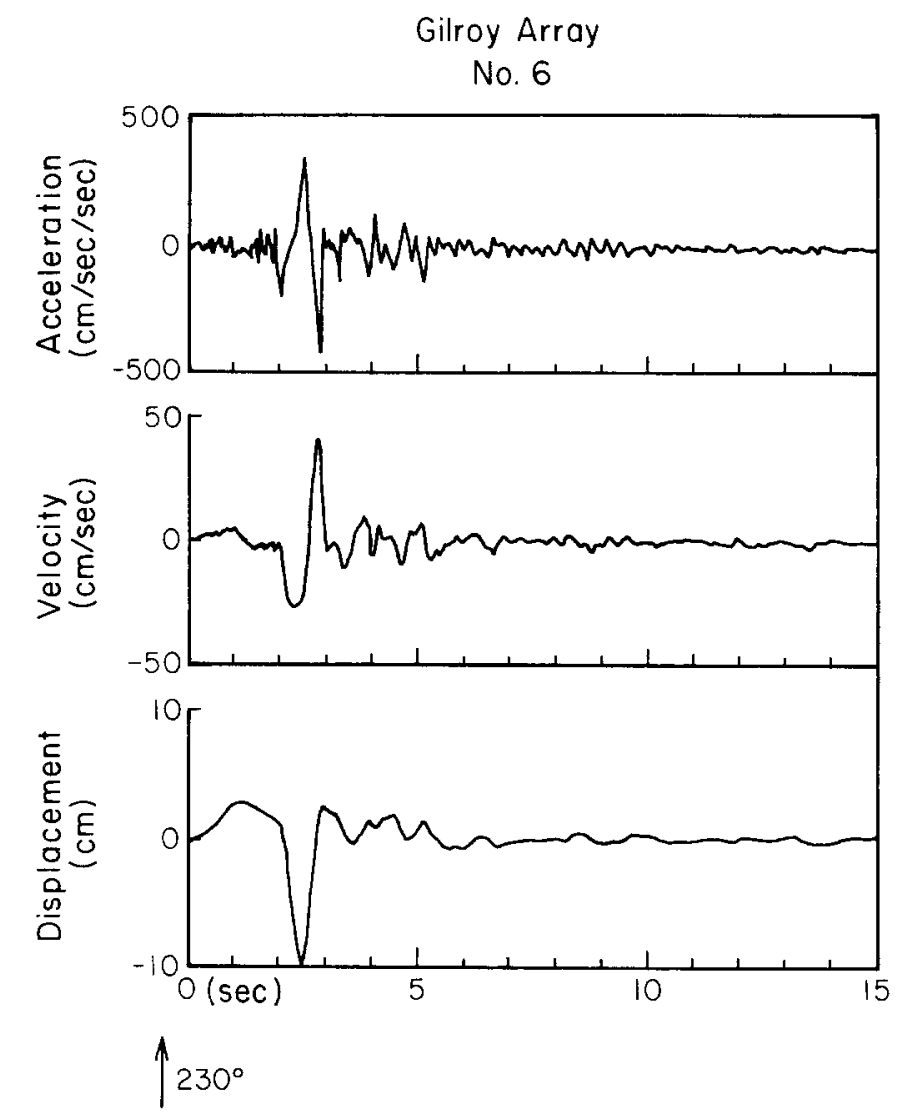

Fig. 4. The corrected acceleration, integrated velocity, and displacement at Gilroy station 6 . The positive motion is along $\mathrm{N} 230^{\circ} \mathrm{E}$.

ever, in the vertical traces, these coherent phases can be recognized only in stations SMCC and GA-6. It appears that some earlier arrivals in stations GA-4 and GA-3 (about $0.8 \mathrm{sec}$ earlier, indicated as upward dashed arrows) are more likely the $S$ waves. GA-4 and GA-3 are near the node of $S H$ waves or the maximum of $P$ waves, and $P$ to $S V$ converted energy may explain the earlier arrival times. Angstman $e t a l$. (1979) interpret these as an $S-P$ converted phase due to the low velocity in the alluvium near the receiver.

\section{Strong Ground Motion Modeling}

A finite dislocation source along a $10 \times 8 \mathrm{~km}^{2}$ fault is used to simulate the horizontal strong ground displacements. The velocity structure (listed in Table 2) 
used to locate the aftershocks near the Gilroy array area by Lee et $a l$. (1979) is adapted to calculate the theoretical seismograms. The full point source responses up to $2 \mathrm{~Hz}$ are calculated by the discrete wavenumber, finite-element technique (Olson, 1978; Hartzell and Helmberger, 1981). Figure 6 shows the $S H$ displacements

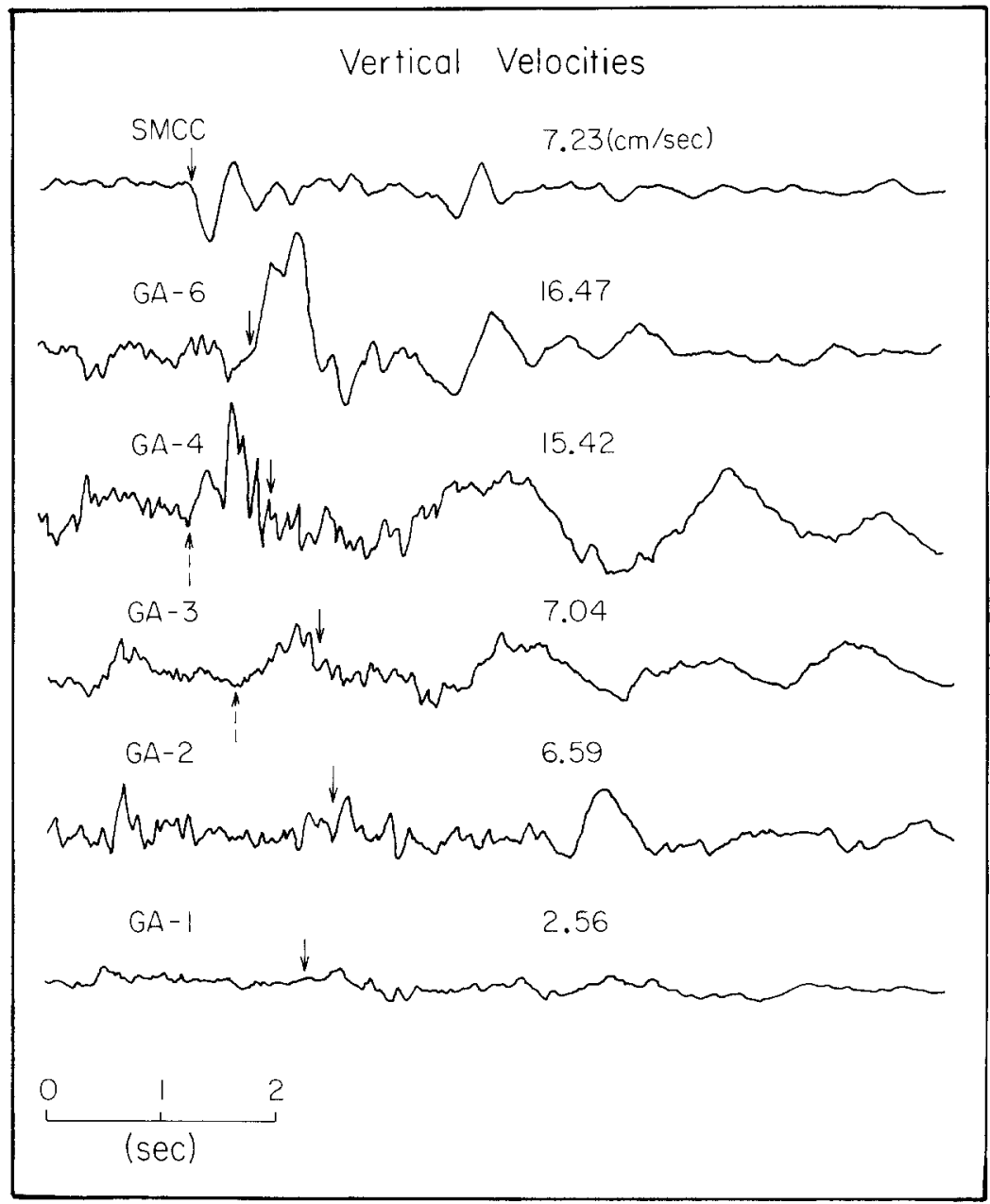

FIG. 5. Vertical components of the integrated velocity from SMCC and the Gilloy array stations. The solid arrows indicate the expected $S$ arrivals determined from horizontal components. The dashed arrows marked in GA-4 and GA-3 indicate the possible converted phases which arrived earlier than the $S$ waves.

TABLE 2

The Velocity STRUCture

\begin{tabular}{cccc}
\hline $\begin{array}{c}\text { Thickness } \\
(\mathrm{km})\end{array}$ & $\begin{array}{c}P \text { Velocity } \\
(\mathrm{km} / \mathrm{sec})\end{array}$ & $\begin{array}{c}S \text { Velocity } \\
(\mathrm{km} / \mathrm{sec})\end{array}$ & $\begin{array}{c}\text { Density } \\
\left(\mathrm{gm} / \mathrm{cm}^{3}\right)\end{array}$ \\
\hline 0.5 & 3.0 & 1.5 & 2.4 \\
2.5 & 5.0 & 2.8 & 2.7 \\
9.0 & 5.7 & 3.3 & 2.78 \\
- & 6.9 & 3.9 & 3.0 \\
\hline
\end{tabular}

from a strike-slip fault at various distances and depths. For the sources deeper than $4 \mathrm{~km}$, which is very likely the case in this earthquake; the responses reflect mainly the source character.

Our finite-source model is simply the sum of the responses due to point sources 
along the fault with proper time lags determined by the arrival of rupture front (Heaton, 1982). We use $1 \times 1 \mathrm{~km}^{2}$ as the basic grid size in computing the step responses. In order to have finer grids efficiently, we linearly interpolate the Green's functions for a $0.5 \times 0.5 \mathrm{~km}^{2}$ grid from the adjacent points. A 0.5 -sec symmetric triangular time function is assumed to represent the time derivative of the dislocation time history of each point on the finite fault. The dislocation along the fault, or the final slip, and the fault area can be varied easily by adjusting the moment of each grid point source. Once the faulting initiates, it propagates at a constant speed and forms a circular rupture front, terminating when it reaches the edge of the finite fault boundary.

Our preferred dislocation model $\mathrm{N} 1$ derived by trial-and-error modeling is illustrated in Figure 7. We essentially constrain the fault size by the signal durations, especially from the more distant stations, such as GA-1, GA-2, GA-3, and GA-4. The rupture velocity is then adjusted by the relative amplitudes among these stations, particularly the contrast between the northern station SMCC and the southern

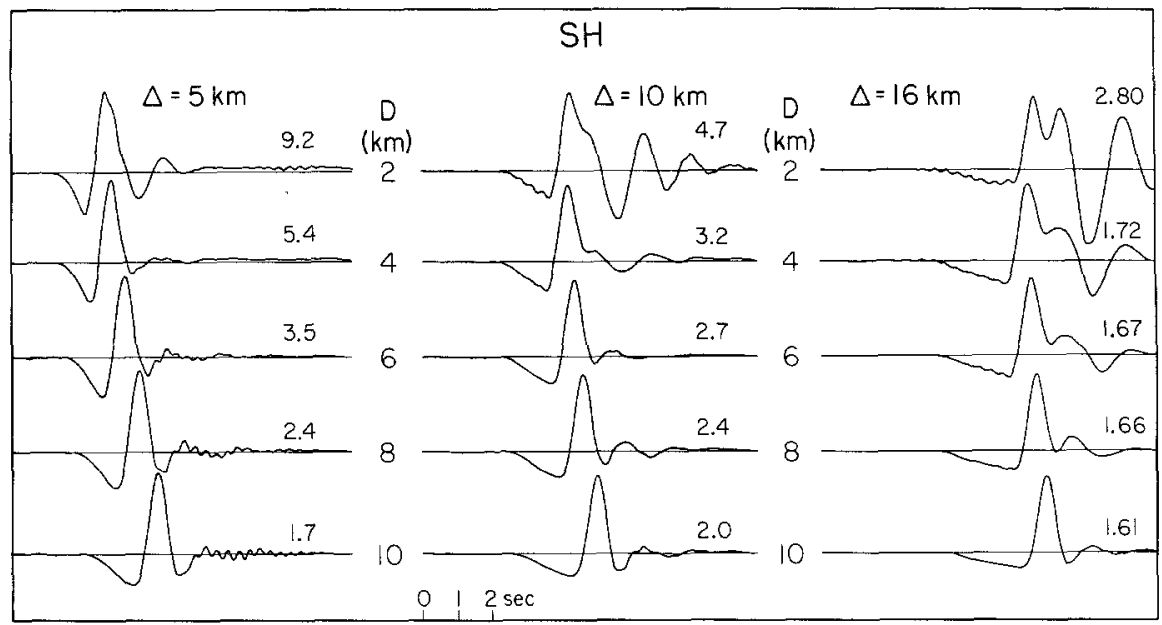

Fig. 6. The synthetic $S H$ displacements for a pure strike-slip source at various distances $(5,10$, and $16 \mathrm{~km}$ ) and depths (from 2 to $10 \mathrm{~km}$ ). The Green's functions are generated by discrete wavenumber finite-element technique and represent the full wave field for the structure listed on Table 2. A 1-sec triangular time function $(0.5,0.5)$ is convolved with the Green's function to obtain the displacement.

station GA-6. The hypocenter is located at a depth of $8 \mathrm{~km}$. The rupture started at that point and propagated with a velocity of about $2.8 \mathrm{~km} / \mathrm{sec}$. A $0.3 \mathrm{~km} / \mathrm{sec}$ variation of the rupture velocity can still generate acceptable amplitudes without significant change of the fault size. This model suggests that the major faulting responsible for the near-source ground displacements accounted for 60 per cent of the total moment and took place in a small area of about $2 \mathrm{~km} \times 3 \mathrm{~km}$ just south of the hypocenter. The rupture propagated mostly toward station GA-6, which explains part of high-amplitude waveforms recorded in GA-6.

Figure 8 illustrates the comparison of the observed horizontal ground displacements versus the synthetics for this model. An Ormsby filter (high pass 0.05 to 0.25 $\mathrm{Hz}$ ) has been applied to both observed and synthetic displacements shown in Figure 8. In general, the waveforms and amplitudes agree quite well. The transverse components of GA-3 and GA-4 are close to a node and are sensitive to small variations. Our model can not predict the observed transverse amplitudes of these two stations. If we exclude the transverse components of GA-3 and GA-4, the average seismic moment for the horizontal components is about $3.5 \times 10^{24}$ dyne-cm. 
A maximum slip of about $1.2 \mathrm{~m}$ is obtained near the hypocenter. The total rupture length along the strike direction is about $6 \mathrm{~km}$, and the fault area is about $40 \mathrm{~km}^{2}$. The stress drop near the hypocenter is 140 bars, but if we average over the entire source area it would be about 30 bars. From our nonuniform dislocation model, we can consistently predict almost zero slip on the free surface. Table 3 summarizes the source parameters for our preferred finite-source model.

In order to demonstrate how the fault dislocation affects the array records, we show a uniform dislocation model, U1. This model has the same fault length as model $\mathrm{N} 1$, but the final dislocation of $17 \mathrm{~cm}$ is uniformly distributed. The hypocenter is located at the same place as in model N1. Figure 9 shows the synthetics for model U1. Due to larger rupture area, the waveforms are much broader for the stations further away from the fault, such as stations GA-4, GA-3, GA-2, and GA-1. The waveforms at station GA-6 are fit reasonably well, since they are not particularly sensitive to the size of the fault. Most of the observed signal durations from the

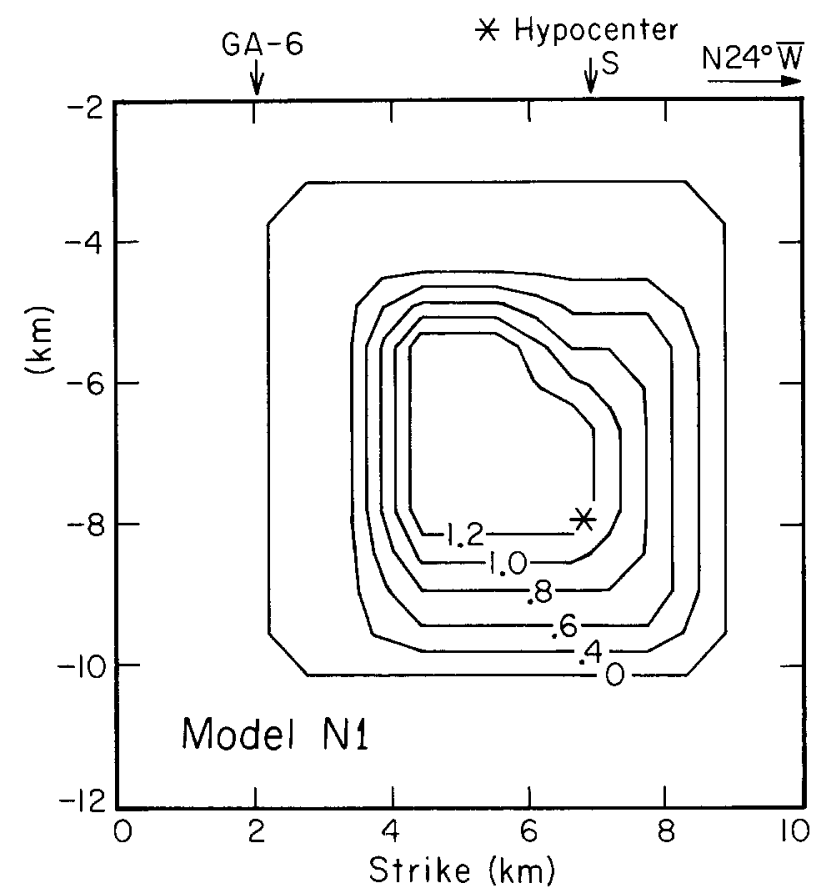

FIG. 7. The dislocation distribution along the fault in our preferred model. The units are meters. $S$ is the epicenter indicated in Figure 3.

array data suggest that the rupture duration was shorter than that implied by model U1. Thus the high-amplitude records in GA-6 are not necessarily caused by a long fault. A slower rupture might accompany the source process at the end, but in terms of the beginning $7 \mathrm{sec}$ of motion, we prefer the concentrated dislocation source model N1 to explain what we have observed.

Bouchon (1982) derived a uniform dislocation fault model for Coyote Lake earthquake from the waveform modeling in transverse components at stations GA6, SMCC, and the broadband seismogram recorded at Berkeley (about $107 \mathrm{~km}$ from the epicenter). Bouchon's source model has a fault length of $14 \mathrm{~km}$ and extends from the depth of 1 to $10 \mathrm{~km}$. The final slip of 15 to $20 \mathrm{~cm}$ was suggested, and the rupture velocity was determined to be $2.6 \mathrm{~km} / \mathrm{sec}$. We argue that Bouchon's fault model is similar to U1 model shown in Figure 9 but with even a larger fault area, 


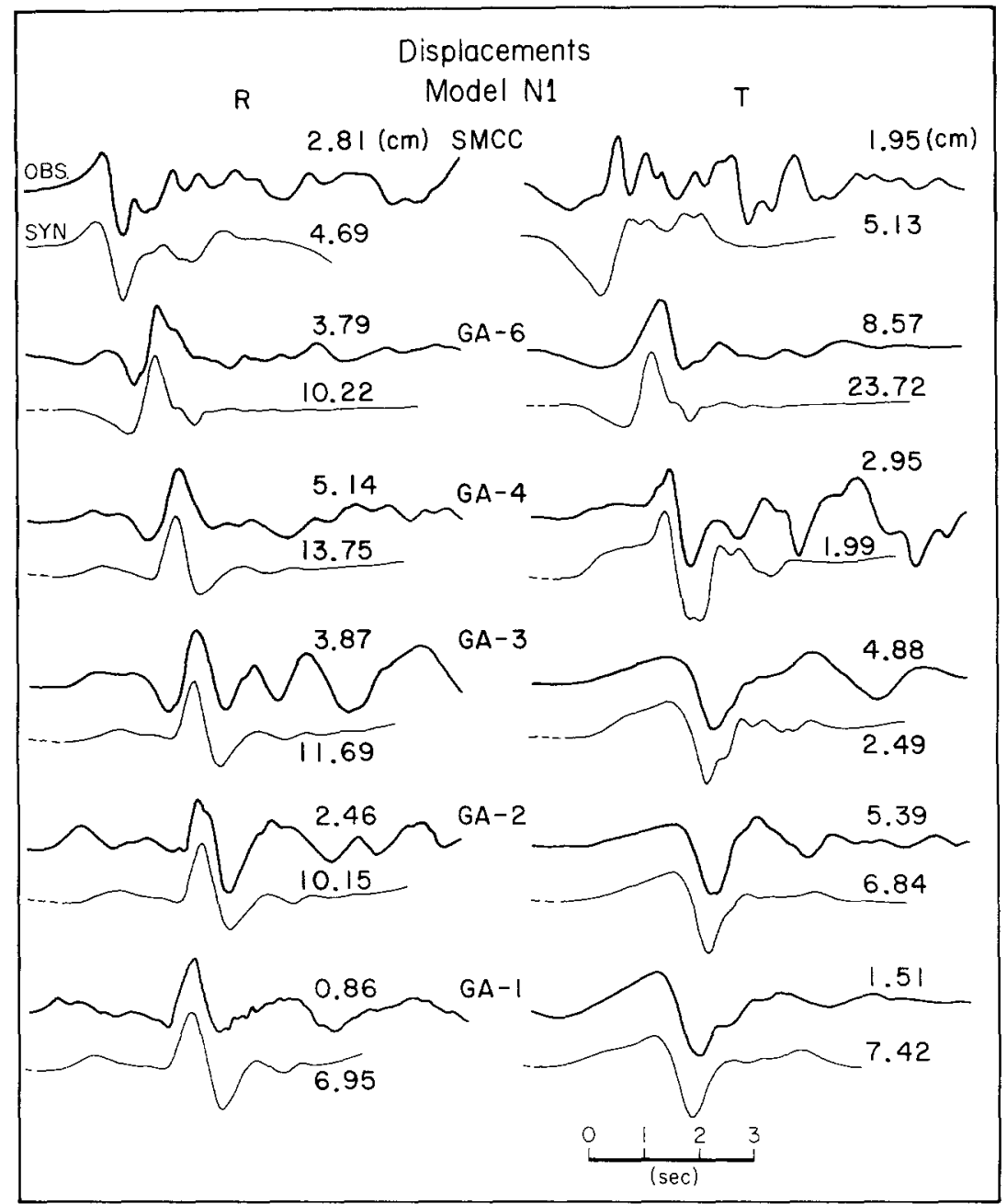

FIG. 8. The observed radial and transverse displacements compared with synthetics for the dislocation model N1. The dashed trace in the beginning of the synthetic seismogram is the discrepancy in the travel time. The number associated with each station indicates the displacement in centimeters. The synthetic seismograms are calculated for a moment of $10^{25}$ dyne-cm, hence the average seismic moment is $3.5 \times$ $10^{25}$ dyne-cm.

TABLE 3

Source Parameters

\begin{tabular}{ll}
\multicolumn{2}{c}{ SoURCE PARAMETERS } \\
\hline Local magnitude & 5.9 \\
Seismic moment & $3.5 \times 10^{24}$ dyne-cm \\
Focal mechanism & strike $=\mathrm{N} 24^{\circ} \mathrm{W}$ \\
& dip $=80^{\circ}$ \\
& slip $=176^{\circ}$ \\
Fault size* & $40 \mathrm{~km}^{2}$ \\
Rupture speed & $2.8 \mathrm{~km} / \mathrm{sec}$ \\
Hypocenter depth & $8 \mathrm{~km}$ \\
Maximum dislocation & $120 \mathrm{~cm}$ \\
Average stress drop & $30 \mathrm{bars}$ \\
\hline
\end{tabular}

* The fault size here regards the area with slip greater than zero. 
which would produce much broader waveforms for stations not located on the fault. Bouchon used a high-frequency stopping phase identified at Berkeley broadband seismogram to determine the fault size. We also argue that at the distance of about $100 \mathrm{~km}$, this high-frequency phase could also be the Moho-reflected wave. The Green's function at this distance is very sensitive to the detailed velocity structure.

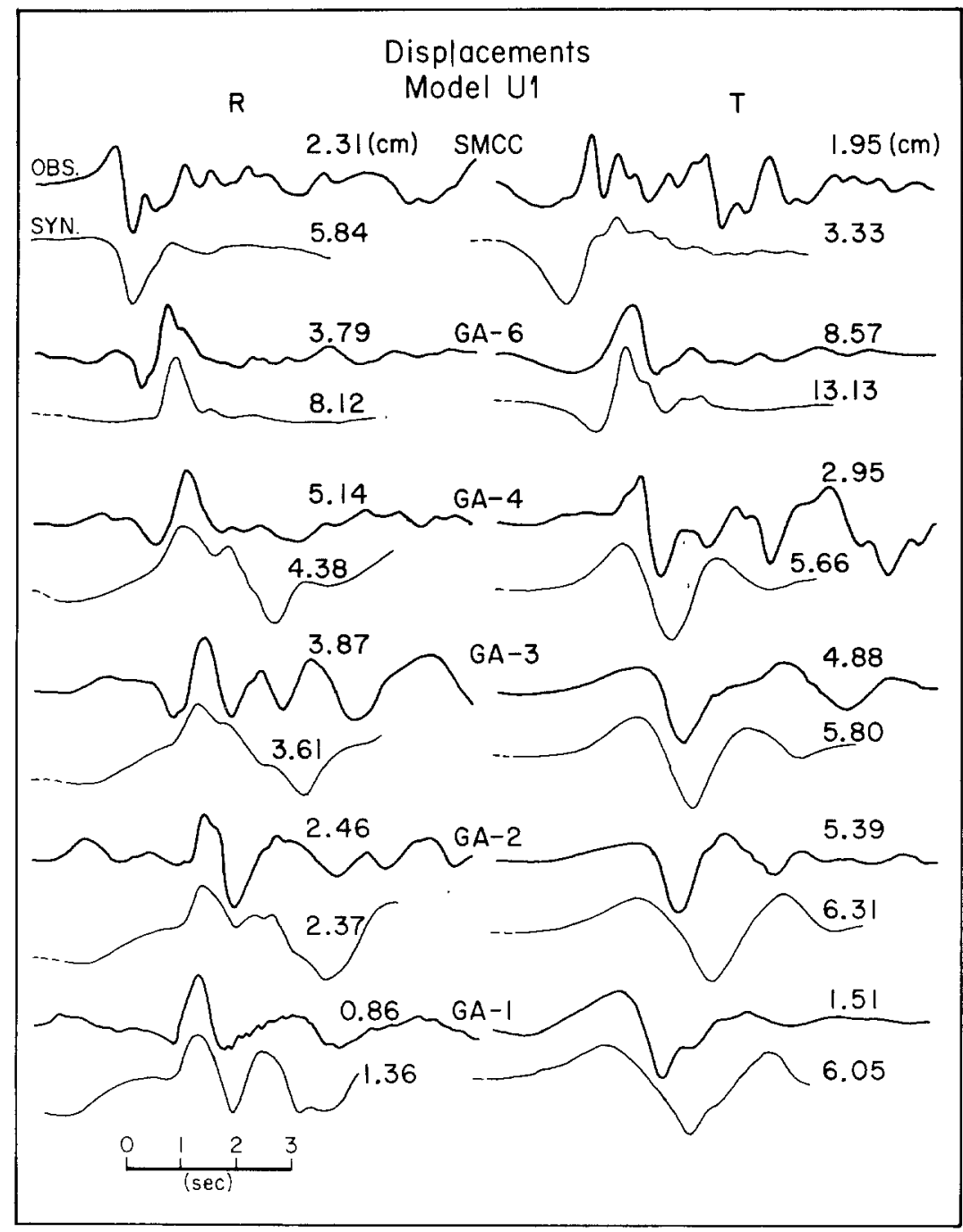

FIG. 9. The observed horizontal displacements and synthetics from model U1. The displacements are indicated in centimeters. The synthetic seismograms are calculated for a moment of $10^{25}$ dyne-cm.

Unless we know the crustal model very well, it is difficult to identify the source phase in Berkeley records. Instead, we will demonstrate the small source character suggested in the far-field by modeling the teleseismic data in the following section.

\section{Regional and Teleseismic Data}

In order to test our finite-source model, we synthesize the waveforms recorded at both regional aistances $\left(1^{\circ}\right.$ to $\left.12^{\circ}\right)$ and teleseismic distances $\left(30^{\circ}\right.$ to $\left.90^{\circ}\right)$ from model N1.

The long-period body waves recorded at regional distances can be represented by the combinations of $P_{n}$ and $P_{L}$ phases, or $P_{n 1}$ waves, which have propagated through 
a single crustal layer over a half-space (Helmberger and Engen, 1980; Wallace and Helmberger, 1981). Due to the long-period character of the $P_{n 1}$ waves, they can not be used to resolve the source time function. However, $P_{n 1}$ waves can provide good constraints on the fault orientation and the seismic moment. For simplicity, a trapezoidal time function with $3 \mathrm{sec}$ duration is assumed to represent the far-field source time history (see Figure 10). The observed and the synthetic $\boldsymbol{P}_{n 1}$ waves for the Coyote Lake earthquake are shown in Figure 10. The station information is listed in Table 4 . We found good agreement in waveshapes and amplitudes. The

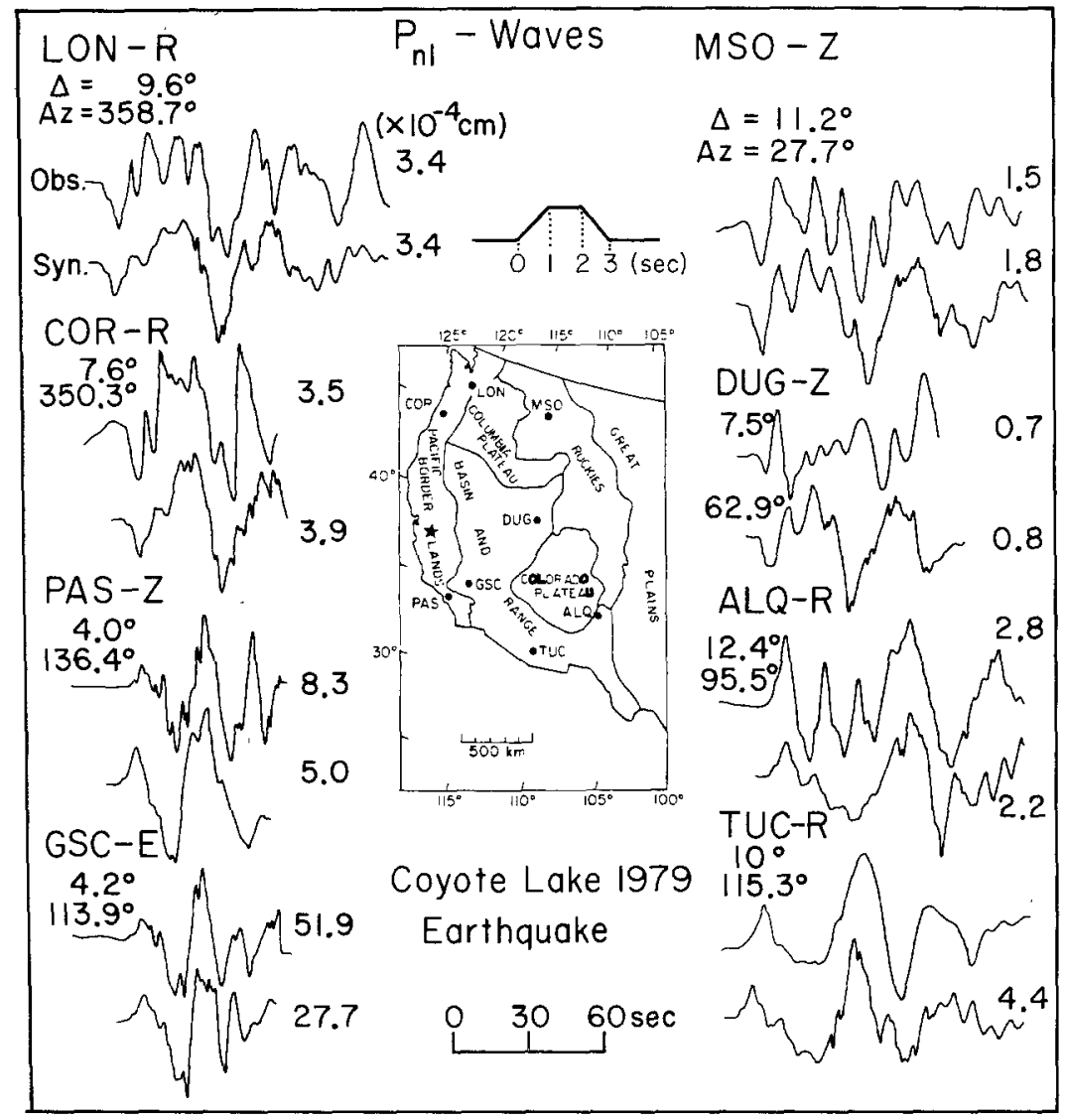

FIG. 10. The observed $P_{n 1}$ waves versus synthetics for model N1. The number associated with each station is the absolute ground displacement. The synthetics are calculated for a moment of $3.5 \times 10^{24}$ dyne-cm. No amplification factor is available for amplitude correction at station TUC.

TABLE 4

STATIONS FOR $P_{n 1}$ WAVES

\begin{tabular}{ccrc}
\hline Station Name & Epicentral Distance & Azimuth & Component $^{*}$ \\
\hline ALQ & 12.4 & 95.5 & $R$ \\
COR & 7.6 & 350.3 & $R$ \\
DUG & 7.5 & 62.9 & $Z$ \\
GSC & 4.2 & 113.9 & $E$ \\
LON & 9.6 & 358.7 & $R$ \\
MSO & 11.2 & 27.7 & $Z$ \\
PAS & 4.0 & 136.4 & $Z$ \\
TUC & 10.0 & 115.3 & $R$ \\
\hline
\end{tabular}

* $Z$, vertical component; $E$, east-west component; and $R$, radial component. 
seismic moment used to calculate the amplitude is $3.5 \times 10^{24}$ dyne-cm, which is the moment we obtained for the model N1. No attenuation is considered in this synthetic calculation. The comparable amplitudes of the observations versus synthetics indicate that no significant attenuation accompanies the propagation of $P_{n 1}$ waves.

The teleseismic body waves $\left(30^{\circ}\right.$ to $\left.90^{\circ}\right)$ are generally accepted as the more reliable data for describing the overall motion during the earthquake process. An important question we would like to answer is whether the finite-source model can predict the teleseismic seismograms. For the Coyote Lake event, due to the nearly pure strike-slip mechanism and relatively small moment, few teleseismic $P$ waves were observed. Here, we simply generate the teleseismic long-period $P$ (vertical component) and $S H$ waves for our finite-source model N1. The stations used are listed in Table 5. The structure we considered is a half-space $(\alpha=6.0 \mathrm{~km} / \mathrm{sec}, \beta=$ $3.5 \mathrm{~km} / \mathrm{sec}$, and $\rho=2.78 \mathrm{gm} / \mathrm{cm}^{3}$ ) and thus the seismograms are assumed to consist of $P, p P$, and $s P$ for vertical $P$ waves and $S, s S$ for $S H$ waves (Langston and Helmberger, 1975). The far-field source time function is calculated from the finitesource model N1 for each station (Heaton, 1982).

TABLE 5

Teleseismic Stations Used in this Study

\begin{tabular}{lrrl}
\hline Station Name & $\begin{array}{c}\text { Epicentral } \\
\text { Distance }\end{array}$ & Azimuth & \multicolumn{1}{c}{ Component* $^{*}$} \\
\hline ALE & 49.5 & 8.5 & $P-L Z, S H$ \\
BLA & 32.6 & 77.1 & SH \\
BOG & 54.0 & 114.8 & $P-S Z$ \\
CAR & 55.6 & 103.8 & $P-L Z, P-S Z$ \\
GDH & 48.1 & 26.3 & $S H$ \\
LPS & 36.7 & 119.7 & $P-L Z, P-S Z$ \\
MBC & 39.2 & 0.8 & $P-L Z, S H$ \\
OGD & 36.3 & 68.9 & $P-L Z, S H$ \\
OTT & 35.0 & 61.6 & $S H$ \\
RES & 39.7 & 10.7 & $S H$ \\
SCH & 40.8 & 46.3 & $S H$ \\
SCP & 33.9 & 70.0 & $S H$ \\
SJG & 51.8 & 95.6 & $P-S Z$ \\
WES & 38.5 & 66.1 & $S H$ \\
\hline
\end{tabular}

${ }^{*} P$-LZ, long-period vertical $P$ component; $P$-SZ, short-period vertical $P$ component; and $S H, S H$ waves.

Figure 11 illustrates the observed and synthetic vertical $P$ and $S H$ waveforms. This comparison shows that our finite-source model can predict the beginning 10 sec of motion well, but it cannot predict the later arrivals. The seismic moment is about $3.6 \times 10^{24}$ dyne-cm. The average far-field source time function form model N1 is about 2 sec. Nabelek (personal communication) has inverted these teleseismic data for source parameters and found that the waveforms can be matched better by three separate events. His preferred solution is described in Figure 12, which includes the main shock (the first event) and two aftershocks 6 and 12 sec later. Our finitesource model is very close to Nabelek's first event in terms of source time duration and seismic moment. The fault orientation of Nabelek has about the same dip angle and slip as ours, but the strike is rotated $12^{\circ}$ further to the west. In Nabelek's solution, the first event, or the main shock, has a moment about 3 times larger than the other two events. The second and third events, which have very different fault geometry from the first earthquake, cannot be recognized in the near-source ground 


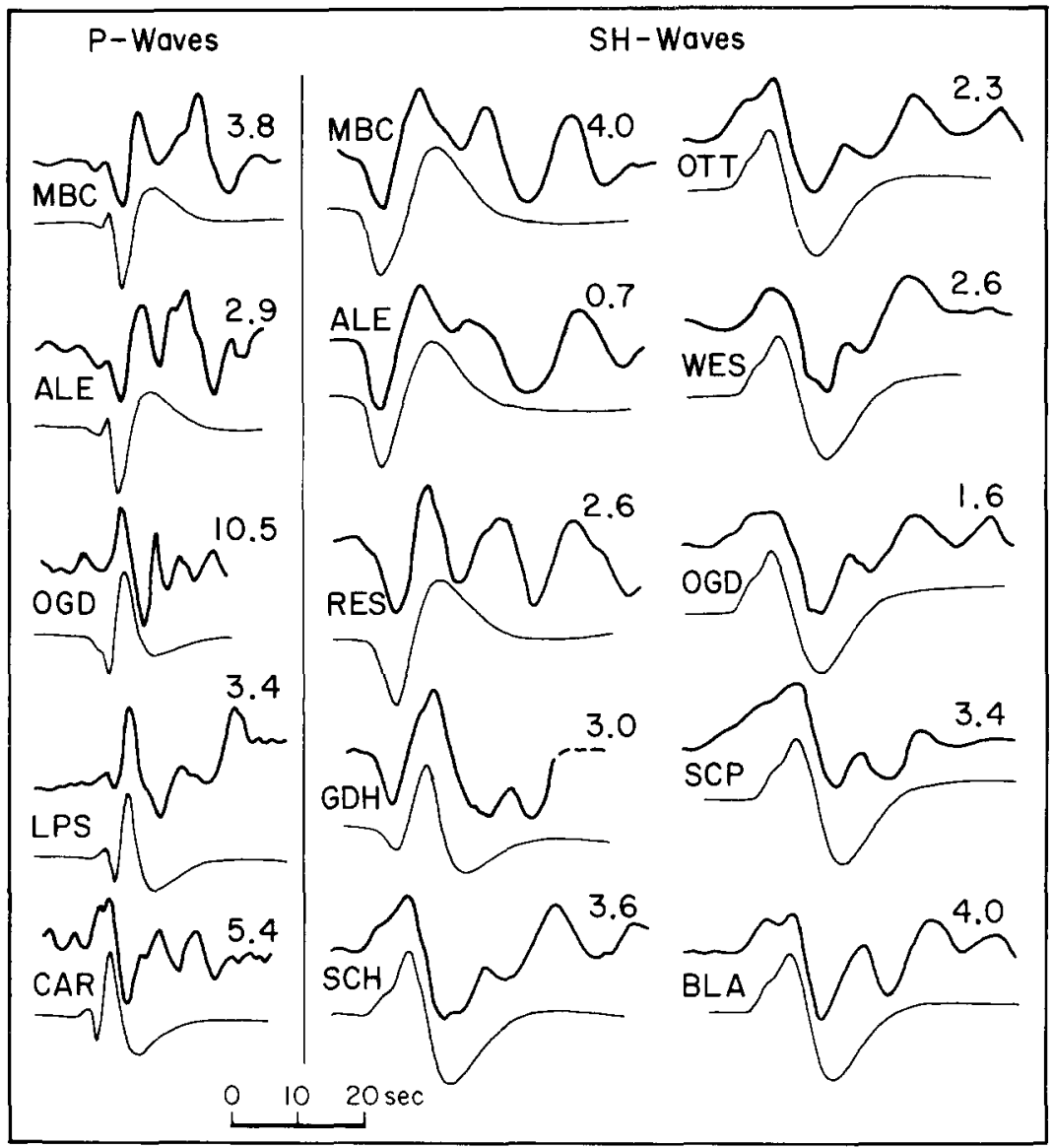

FIG. 11. The teleseismically observed vertical $P$ and $S H$ waves versus synthetics for the finite-source model N1. The numbers indicate the seismic moment in units $10^{24}$ dyne-cm for each station.

\section{Source Time Function}

(1)

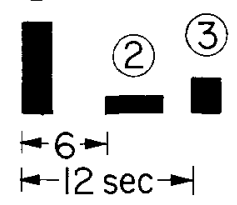

(1)

$$
\begin{aligned}
\phi & =324^{\circ} \\
\delta & =77^{\circ} \\
\lambda & =171^{\circ} \\
M_{0} & =3.3 \times 10^{24} \text { dyne } \cdot \mathrm{cm}
\end{aligned}
$$

(2)

$$
\begin{aligned}
\phi & =340^{\circ} & \phi & =49^{\circ} \\
\delta & =62^{\circ} & \delta & =78^{\circ} \\
\lambda & =85^{\circ} & \lambda & =222^{\circ} \\
M_{0} & =1 \times 10^{24} & M_{0} & =1 \times 10^{24}
\end{aligned}
$$

(3)

FrG. 12. The multiple sources determined by Nabelek (personal communication). 
motion records. According to the far-field source parameters determined by Nabelek, the second event is probably too small to be seen in the near-field, but the third event is expected to produce about one-third of the near-source ground motions as the main event. The possible explanation for this discrepancy is either the third source is outside the strong ground motion array and rupturing away from it or the source process is too smooth to produce significant near-source ground motions.

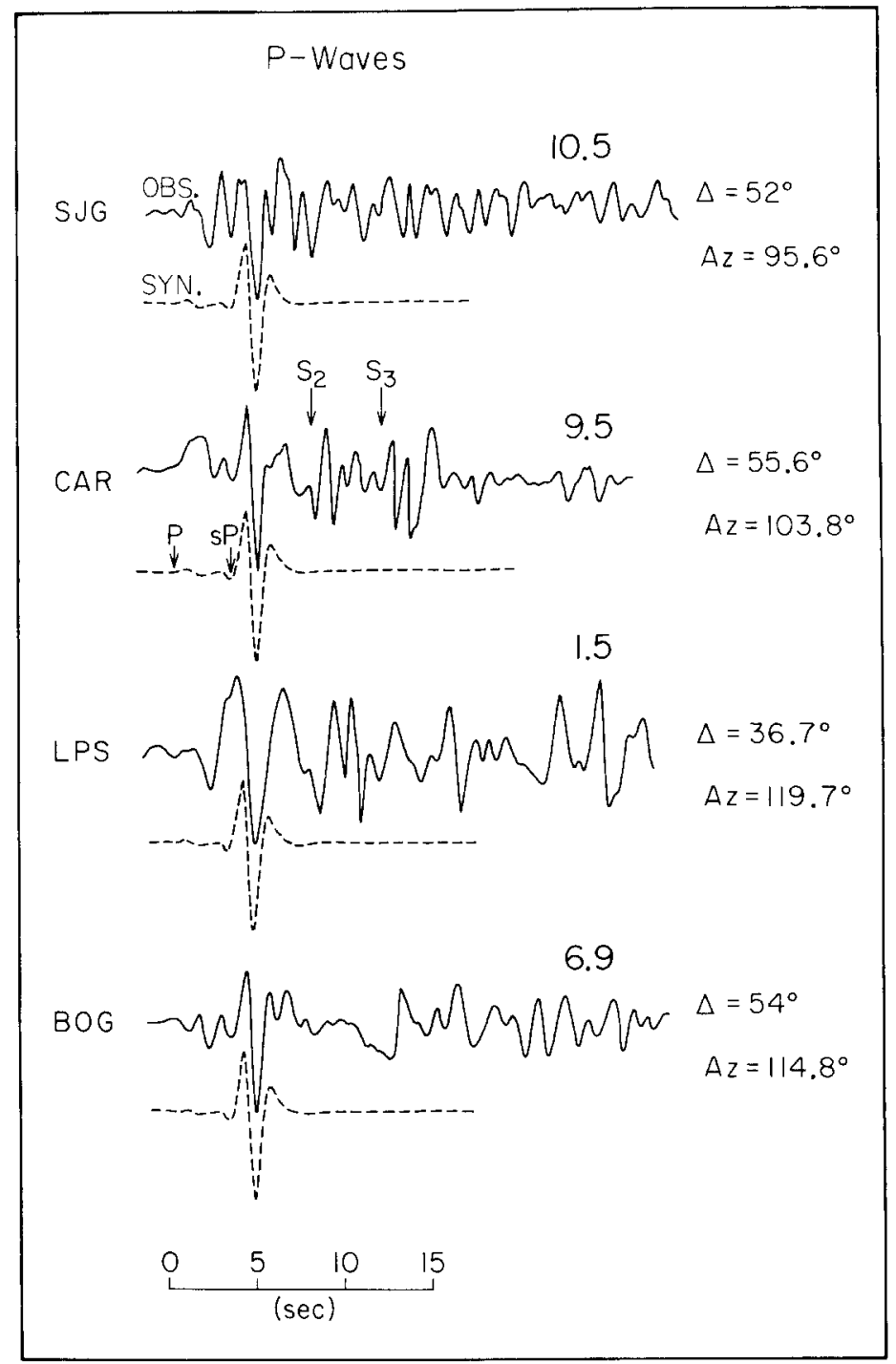

Fig. 13. The teleseismic short-period vertical $P$ waves and synthetics for the finite-source model, N1. $S_{2}$ and $S_{3}$ at station CAR indicate the possible phases corresponding to the second and third events in Nabelek's solution. The numbers are the seismic moments in units $10^{24}$ dyne-cm.

Few teleseismic stations recorded good-quality short-period vertical seismograms. The stations in south America show rather high short-period amplitude when compared with stations in other azimuths. Figure 13 shows the seismograms from four of these stations, which yield azimuthal range of about $20^{\circ}$. The impulsive arrivals seen about $3 \mathrm{sec}$ after the direct $P$ waves are very coherent and can be predicted by our finite-source model as the $s P$ phase. The seismic moment deter- 
mined from the amplitude ratio is indicated for each station, and is higher than the averaged moment from long-period waves. Station LPS may have some instrument calibration problem, since the response is not near $1 \mathrm{sec}$. The later waves appearing in the seismograms (indicated as $S_{2}$ and $S_{3}$ at CAR in Figure 13) may be the second and third events according to Nabelek's solution, since the delay time is about 6 and $12 \mathrm{sec}$, respectively. One of the more difficult problems in working with the shortperiod teleseismic data is the uncertainty introduced by the effects of velocity structure. In this study, we simply use a half-space structure at both source and receiver; at the stations like Caracas (CAR), for which the structure appears rather transparent (Burdick and Langston, 1977), this approximation may be adequate. In spite of complexities, the teleseismic short-period data contain information which may provide close correlation with the near-source ground motions, particularly in the phases associated with high-stress drop events.

\section{Discussion}

The source model we determined from the strong ground motion data can predict reasonably well the $P_{n 1}$ waves in regional distances and the beginning features of the teleseismic seismograms. However, some questions are raised concerning a unified source model which can explain both near- and far-field data simultaneously. First, the basic difference between our preferred model N1 and Nabelek's main shock solution is the $12^{\circ}$ strike direction. The question is how well we can resolve this difference from either near- or far-field observations. We have generated $P_{n 1}$ waves from Nabelek's source orientation (with strike $=324^{\circ}$, dip $=77^{\circ}$, and slip $=$ $171^{\circ}$ ); the major difference from model N1 appears at the nodal station DUG. However, neither our preferred model, N1, or Nabelek's solution could predict a satisfactory waveform at this station. A similar situation arises at the teleseismic nodal stations. Since the waveforms are barely above the noise level at these stations, we cannot argue the resolution based upon them. For the strong ground motion data, the problem is different. The finite-source model N1 is constructed with a fixed-fault geometry (with strike $=336^{\circ}$, dip $=80^{\circ}$, and slip $=176^{\circ}$ ). As we mentioned earlier, some qualitative judgments about the waveform coherency and the radiation pattern are considered in the trial-and-error modeling process. If we simply use the same dislocation configuration of model $\mathrm{N} 1$ but adopt the fault orientation of Nabelek (personal communication), the amplitude of the radial component of the southeast station GA-6 increases, which is not consistent with the observations. On the other hand, the predicted amplitude ratio of transverse versus radial for stations GA-4 and GA-3 increases, which fits the data better. The signal duration and the waveshape can be reproduced on most of the stations reasonably well, except for the transverse component of station GA-4, which is near the $S H$ node. Therefore, we conclude that the most significant feature in our preferred finite-source model $\mathrm{N} 1$ is the large final slip concentrated to the south of the hypocenter. The uncertainty of the fault geometry is not well resolved within the acceptable variation in the amplitudes.

Second, we raise a question of how distinguishable the far-field waveform can be for a uniformly distributed dislocation model. A close comparison of the source factors we have considered and their effects on the far-field waveforms are discussed below.

Figure 14 shows the teleseismic synthetics for stations MBC, OGD, and CAR for four uniform dislocation sources, namely U1, U2, U3, and U4. The synthetics from model $\mathrm{N} 1$ are also displayed in the same figure for comparison. The variables in these four uniform dislocation models are the rupture velocity, the far-field rise time 
of the point dislocation, and the hypocenter location. Based on a total moment of $3.5 \times 10^{24}$ dyne-cm, the average final slip is estimated to be $17 \mathrm{~cm}$ for all the uniform slip models. In model U1, the only difference from model N1 is the uniform slip. At the teleseismic distances, the long-period synthetic waveforms for U1 show no significant differences from model N1, however the amplitudes are slightly reduced. The short-period synthetics for N1 model suggest that the amplitude at CAR is about twice as large as at station MBC due to the southward rupture through a concentrated source. This may explain why only the south American stations recorded high short-period amplitudes. This amplitude contrast is no longer seen for model U1 when the source dislocation is uniformly distributed through a large fault, because the amount of 1-sec energy has been reduced. The observations at

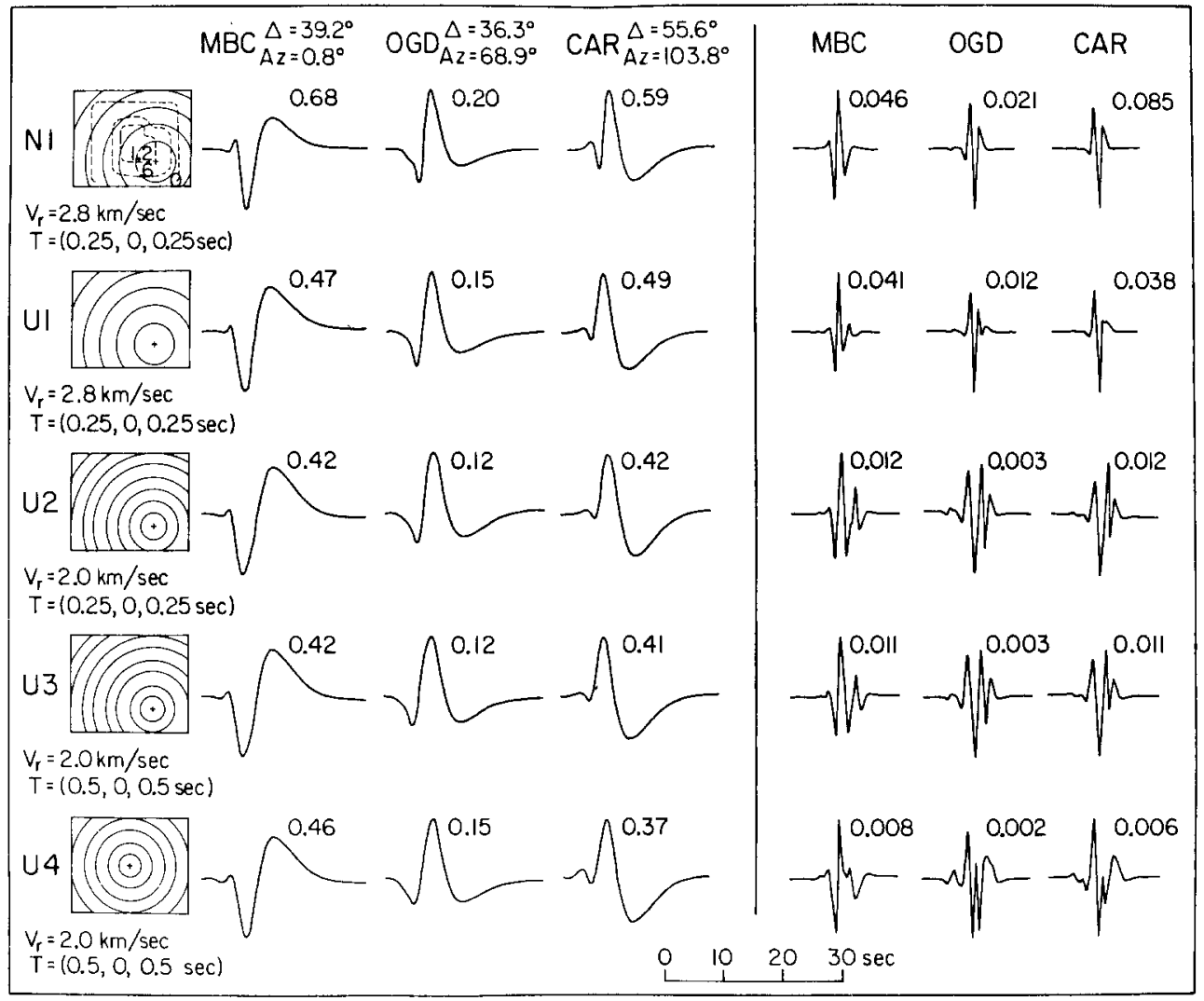

FIG, 14. Synthetic comparison at the teleseismic stations for the uniform slip models, namely U1, U2, U3, and U4. Our preferred model N1 (see also Figure 7) is also illustrated. All the uniform slip models have a final dislocation of $17 \mathrm{~cm}$ along the fault surface. The circular rupture fronts are also illustrated. The numbers are the amplitudes in micrometers calculated for the seismic moment of $5.0 \times 10^{24}$ dynecm.

station CAR show that the amplitude ratio of short period to long period is about 0.3 , which is higher than the predicted of 0.16 in model N1, and 0.07 in U1. Although the synthetics are calculated using a half-space assumption and with $t^{*}=1$, the observed amplitude ratio indicates a high-frequency source. We have shown earlier that the U1 model produces too broad and much longer signal durations for nearsource stations away from the fault, such as GA-4, GA-3, GA-2, and GA-1. Hence, in this case, the near-source array data can provide the best constraints for identifying such a high-frequency source. 
The U2 model has slower rupture velocity $(2.0 \mathrm{~km} / \mathrm{sec})$. The teleseismic longperiod synthetics have slight amplitude change but the waveforms are about the same as model U1. The short-period synthetic seismograms have about 30 per cent of the amplitude compared to U1 model, and the waveforms are more complicated, due to the response to the longer rupture duration. In this case, the amplitude ratio of short period versus long period at station CAR is about 0.02 , which is about one order magnitude smaller than the observation.

In model U3, we consider slower rise time (1-sec triangle). The synthetic seismograms are quite similar to model U2, this simply implies that such difference in the source parameters is not resolvable teleseismically.

A symmetric rupture is shown in model $\mathrm{U} 4$, which has the hypocenter located in the center of the fault. Again, the long-period change is not very significant. The short-period waveform at CAR has the feature of the concentrated source, but the amplitude is only about 10 per cent of that in model N1.

These comparisons suggest that the teleseismic long-period data can hardly distinguish the difference between a uniform or nonuniform dislocation model for the presented fault size, but the short-period data reveal quite significant amplitude differences. The short-period waveforms also show individual difference for some cases. However, in a real earth, these variations can easily be caused by other uncertain parameters, including the source/receiver structures.

\section{Conclusions}

We have learned from this study that the near-source array data can provide good constraints on source parameters. The strong ground motion array data from the 1979 Coyote Lake, California, earthquake suggest that the source initiated at a depth of $8 \mathrm{~km}$ and with about $120 \mathrm{~cm}$ dislocation near the hypocentral area. The rupture is basically toward the south but vanishes after a rupture length of $6 \mathrm{~km}$. The stress drop in the hypocentral area is about 140 bars, but averages about 30 bars over the entire rupture surface. The concentrated dislocation results in the high-frequency-enriched seismograms. Nabelek's (personal communication) inversion solution for the teleseismic data indicates that the Coyote Lake earthquake is a multiple event comprised of three separate earthquakes, in which the first event or the main shock is characterized by high-stress drop and short-source time duration. Our preferred finite-source model reflects only this strong but short rupturing of the main shock. No clear indication of the second and the third events can be found in the near-source ground motions.

\section{ACKNOWLEDGMENTS}

We would like to thank Tom Heaton, Steve Hartzell, Jeff Given, and Hiroo Kanamori for carefully reading the manuscript. Steve Hartzell and David Harkrider assisted in computing the Green's functions. Tom Heaton provided the finite-fault summation programs. The assistance from Terry Wallace and Gladys Engen in computing the $P_{n 1}$ waves is acknowledged. This research is supported by Earth Sciences Section, National Science Foundation PFR-7921769.

\section{REFERENCES}

Angstman B. G., P. K. P. Spudich, and J. Fletcher (1979). The coyote Lake earthquake: 0.42 g acceleration from an S-P converted phase, Trans. Am. Geophys. Union 60, S121.

Archuleta, R. (1979). Rupture propagation effects in the Coyote Lake Earthquake, EOS 60, S122.

Bouchon, M. (1982). The rupture mechanism of the Coyote Lake earthquake of 6 August 1979 inferred from near-field data, Bull. Seism. Soc. Am. 72, 745-757.

Brady A., P. Mork, V. Perez, and L. Porter (1979). Processed data from the Gilroy Array and Coyote 
Creek records, Coyote Lake, California earthquake 6 August 1979, U.S. Geol. Surv., Open-File Rept. 81-42.

Burdick, L. J. and C. A. Langston (1977). Modeling crustal structure through the use of converted phases in teleseismic body-wave forms, Bull. Seism. Soc. Am. 67, 677-691.

Hartzell S. and D. Helmberger (1981). Strong motion modeling of Imperial Valley earthquake of 1979 (in press).

Heaton, T. H (1982). The 1971 San Fernando earthquake: a double event (in press).

Helmberger D. G. and G. Engen (1980). Modeling the long-period body waves from shollow earthquakes at regional ranges, Bull. Seism. Soc. Am. 70, 1699-1714.

Herd D. G., R. J. McLaughlin, A. M. Sarna-Wojcicki, M. M. Clark, W. H. K. Lee, R. V. Sharp, D. H. Sorg, W. D. Stuart, P. W. Harsh, and R. K. Mark (1979). Surface faulting accompanying the August 6, 1979 Coyote Lake earthquake, EOS 60, 890.

Joyner W. B., R. E. Warrick, and T. E. Fumal (1981). The effect of Quaternary alluvium on strongground motion in the Coyote Lake, California earthquake of 1979, Bull. Seism. Soc. Am. 71, 1333.

Langston, C. A. and D. V. Helmberger (1975). A procedure for modeling shallow dislocation source, Geophys. J. 42, 117-130.

Lee, W., D. Herd, V. Cagnetti, W. Bakun, and A. Rapport (1979). A preliminary study of the Coyote Lake Earthquake of August 6, 1979 and its major aftershocks, U.S. Geol. Surv., Open-File Report. 791621.

Olson, A. H. (1978). Synthesizing ground motion using a discrete wavenumber/finite element representations, Trans. Am. Geophys. Union 59, 1128.

Uhrhammer, R. (1980). Observations of the Coyote Lake, California earthquake sequence of August 6, 1979, Bull. Seism. Soc. Am. 70, 559-570.

Wallace, T. and D. V. Helmberger, and G. Mellman (1981). A technique for the inversion of regional data in source parameter studies, J. Geophys. Res. 86, 1679-1685.

\section{Seismological Laboratory}

California Institute of Technology

Pasadena, California 91125

Contribution No. 3763

Manuscript received 14 April 1982 